\author{
Military Technical College \\ Kobry El-Kobbah, \\ Cairo, Egypt.
}

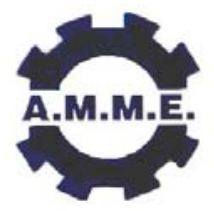

\author{
$13^{\text {th }}$ International Conference \\ on Applied Mechanics and \\ Mechanical Engineering.
}

\title{
STUDY ON OPTIMIZATION OF COMPOSITE CONICAL STRUCTURES FOR CRASHWORTHINESS APPLICATIONS
}

\author{
ALJIBORI ${ }^{1}$ H.S.S.
}

\begin{abstract}
In the last decade, lightweight energy-absorption structures in airframes and automotive vehicles are increasingly used to meet the crashworthiness requirements with a minimum weight increase. Crashworthiness may be defined as the ability of a vehicle to protect its occupants from death or serious injury in an accident of a given severity.

Composite materials are often used to reduce the weight of structures. In the automotive industry weight reduction is important because fuel consumption is directly related to vehicular weight.

In this paper numerical investigations into the crushing of woven roving laminated conical system have been conducted. Energy absorption capability can be achieved if the longitudinal properties of composite structures are being utilized. This can only be done if the energy absorbing system post failure scenario would be mitigated to be tearing failure mechanism. The system was designed by slipping a solid cone into composite cone. The semi cone angles used were 4, 8, 12, 16 and 20 degrees. The cone height and bottom diameter were kept constant for all cases as $100 \mathrm{~mm}$ and $76.2 \mathrm{~mm}$, respectively. The results demonstrated that the energy was dissipated in the form of friction at the first crush stage, while the post crush stage was dominated by tearing failure mechanisms.
\end{abstract}

\section{KEY WORDS}

Composite, Optimization; tearing mechanisms; Energy absorber; cone

\footnotetext{
${ }^{1}$ Mechanical Engineering Dept, Faculty of Engineering, University of Malaya, 50603 Kuala Lumpur, Malaysia, Email address: Hakimss@um.edu.my.
} 


\section{NOMENCLATURE}

$\begin{array}{ll}\text { SEA } & \text { Specific energy absorption } \\ E_{v} & \text { Crushing energy absorbed per unit volume } \\ \mathrm{P}_{\mathrm{m}} & \text { Mean crush load (average) } \\ \mathrm{P}_{\mathrm{i}} & \text { Initial crushing load } \\ \mathrm{P}_{\max } & \text { Stand for the highest peak load (Maximum) } \\ \mathrm{R} & \text { Load ratio } \\ m & \text { Mass of the structure } \\ \mathrm{H} & \text { Height of the structure } \\ \beta & \text { Semi cone angle } \\ \mathrm{CFE} & \text { Crush force efficiency } \\ \mathrm{D}, \mathrm{d} & \text { Maximum and minimum diameters of cone respectively } \\ \mathrm{W}_{\mathrm{T}} & \text { Total work done } \\ \mathrm{W}_{\mathrm{p}} & \text { Work done at post crush stage } \\ \mathrm{S} & \text { Instantaneous displacement } \\ \mathrm{d}_{\sigma} & \text { The primary damage variable } \\ \mathrm{r}_{\mathrm{o}} & \text { The initial damage threshold } \\ \sigma_{t} & \text { The uni-axial tensile stress } \\ \mathrm{E}_{\mathrm{m}} & \text { Young's modulus } \\ \mathrm{L}_{\mathrm{ch}} & \text { Characteristic length of the finite element mesh } \\ \lambda, & \text { characteristic material parameter for the Oliver model and } \\ \mathrm{D}_{\mathrm{r}} & \text { Damage ratio } \\ W R L & \text { Woven Roving Laminate }\end{array}$

\section{INTRODUCTION}

Today's automobiles present an unprecedented challenge to engineers and designers. The most direct method of reducing fuel consumption and emission is to reduce the weight of the vehicle by using light alloys such as aluminum, magnesium, and composite materials. Fuel savings have been reported to be $0.3 \mathrm{l} / 100 \mathrm{~km}$ per $100 \mathrm{~kg}$ reduction of mass for highway driving conditions and twice as much for city driving [1]. To seek for optimal crashworthiness of structure, nonlinear finite element (FE) method has been extensively employed as an analysis engine, which enables to model complex material constitutive relationships, large deformation and strain rates, and frictional contact etc, with acceptable accuracy. Crashworthiness may be defined as the ability of a vehicle to protect its occupants from death or serious injury in an accident of a given severity. The approaches aimed to improve the energy absorption capability of collapsible structures often leads to some penalties and can be classified in two approaches. The approach based on material properties and the other approaches based on geometrical properties. In high performances automotive, the energy absorbers are used to improve the vehicle safety in case of frontal, rear or lateral impacts. These devices placed between the frame and the chassis, it can reduce the acceleration peaks transmitted to the occupancies. In aerospace field, energy absorbers are used in helicopter sub-floors or in light aircrafts to 
reduce the consequences of an impact with the soil in emergency landing or after an accident [2-4].

It is well understood that composite structures exhibit distinct failure mechanisms in crushing that are dependent upon the material properties, geometry and the loading condition. Because wide-ranging of loading conditions are possible in a crushable energy absorber devices during an impact event, it is important to understand the behaviour of these devices under different loadings, including pushing in loading conditions. However, there is a paucity of experimental and finite element work on the quasi-static as well as dynamic pushing of solid structures into hollow composite thin walled shell structure. The use of composite in designing energy absorption system requires an insight into the failure modes that are unique to these types of materials. Unlike fractures, highly crazed surfaces can transmit energy. Crazes are the first sign of surface tensile failures in thermoplastic materials and gel coat finishes. Crazes appear as clean hairline fractures extending from the surface into the composite. Crazes are not true fractures, but instead are combinations of highly oriented "fibrils" surrounded by voids. Depending on the application, any tear in a material may be considered a failure or some tearing may be allowed, provided the structure can absorb the required energy or carry the specified load. In both cases, a strain-to-failure value is generally used as the tearing criterion. The developed system can also be used in the packaging system of heavy and light goods [5-6]

\section{CRASHWORTHINESS PARAMETERS}

\section{Initial Load and Crush Force Efficiency (CFE)}

The ratio of the initial peak load $\left(\mathrm{P}_{\mathrm{i}}\right)$ to the average load $\left(P_{m}\right)$ was very important because the energy absorber design will depend to a large degree on the ability to support loads. One does not want the initial peak load $(\mathrm{Pi})$ to be much greater than the average crush load $\left(P_{m}\right)$ because large loads would be needed to initiate crushing, and the goal in energy management is to absorb all the energy without imparting large forces to the people involved, The load ratio, which is defined as

$$
R=\frac{P_{i}}{P_{m}}
$$

Another important factor in the study of energy absorption for energy management capabilities is the crush force efficiency (CFE), which can be calculated as

$$
C F E=\frac{P_{m}}{P_{\max }}
$$

where, $P_{\max }$ and $P_{m}$ represent maximum peak load in post-crushing stage and mean crush load, respectively. For optimum crush unit, the CFE should be equal to one. [7] 


\section{Energy Absorption Capability}

The most important parameter that was determined from each crush test was the energy absorption. Energy is the product of the force and distance moved at that force level. Two types of energy absorption, during slipping solid cone into conical shells were measured. These are the energy absorbed per unit mass (Specific energy absorption SEA) and energy absorbed per unit volume (Volumetric Energy $E_{v}$ ). The energy absorbed during crush, was then calculated by integrating under the crush load vs. crush distance curve, when $s$ the final crush length [8-9], the total work done is equal to the area under the loadstroke curve

$$
\mathrm{W}_{\mathrm{T}}=\int_{\mathrm{s}_{\mathrm{p}}}^{\mathrm{s}} \mathrm{P}_{\mathrm{i}} \mathrm{ds}
$$

The work done at post crush stage $\left(\mathrm{W}_{\mathrm{p}}\right)$ can be calculated as:

$$
\mathrm{W}_{\mathrm{P}}=\int_{\mathrm{s}_{\mathrm{p}}}^{\mathrm{s}} \mathrm{P}_{\mathrm{i}} \mathrm{ds} \Rightarrow \mathrm{P}_{\mathrm{m}}\left(\mathrm{S}-\mathrm{S}_{\mathrm{P}}\right)
$$

Energy absorbed per unit mass $(m)$ (i.e. specific energy absorption SEA)

$$
S E A=\frac{W_{P}}{m}
$$

The volume occupied by the WRL (woven roving Laminate) conical shells before crushing can be calculated as

$$
V_{\text {con }}=\frac{\pi H}{12}\left[D^{2}+D d+d^{2}\right]
$$

The energy absorbed per unit volume is:

$$
E_{V}=\frac{p_{m}\left(S-S_{P}\right)}{V_{c o n}}
$$

\section{FINITE ELEMENT ANALYSIS}

Numerical simulation was carried out. The finite element simulation was designed to predict the load-displacement curves, deformation histories and energy absorption capability throughout the E-glass fibre fabricated and semi- cone angles.

\section{Model Development}

LUSAS finite element software performed the numerical simulation for the quasi-static method. Detailed three-dimensional finite element models of glass fibre fabricated and semi-cone angle conical curved composite systems were developed. Composites are somewhat more difficult to model than an isotropic material such as iron or steel. We need to take special care in defining the properties and orientations of the various layers since 
each layer may have different material properties. In this section, finite element techniques used in this study will be described. A complete finite element analysis involves three stages: Pre-Processing, finite element solver and results-processing. Finite element system consists of two parts to perform a full analysis:

- Modeller is a fully interactive pre- and post-processing graphical user interface.

- Solver performs the finite element analysis.

Typical meshes generated, shown in Fig. 1 consist of 6291 nodes, 3168 elements, 5775 nodes, 3168 elements, 5648 nodes, 2624 elements and 5480 nodes, 1960 elements for the semi-cone angles $4,8,12,16$, and 20 respectively. Three-dimensional continuum element $(\mathrm{HX} 16 \mathrm{~L})$, sixteen-nodes quadratic interpolation order with hexahedral element shape, $(\mathrm{HX} 16 \mathrm{~L})$ element was used since this is expected to give accurate stress and strain results. This type of element was chosen for modelling these systems for static non-linear analysis prediction. Each node has six degrees of freedom, which include three displacements, $u_{x}, u_{y}, u_{z}$, and three rotation components, $\varnothing_{x}, \varnothing_{y}, \varnothing_{z}$. The laminate was modelled by defining each lamina with material properties, thickness and fibre orientation. Fully fixing degrees of freedom at one end of the model and applying the load at the other end by using a prescribed displacement simulating the testing conditions. Numerical simulation for the specimens is run until complete failure crush load is reached. Typical Sketch of Conical Shell Model shown in Fig 2.

\section{Material Properties}

This section refers to material types used in modelling; orthotropic material properties were used from the library of the LUSAS code for the development of finite element analysis [10]. The basic material properties required for this model are orthotropic elastic properties given in Table 1 and orthotropic damage properties by using Oliver's model as shown later.

\section{Damage Criterion}

Damage is assumed to occur in a material by the initiation and growth of cavities and micro-cracks. The damage properties data chapter allows parameters to be defined which control the initiation of damage and post damage behaviour. In finite element analysis a scalar damage variable is used in the degradation of the elastic modulus matrix. This means that the effect of damage is considered to be non-directional or isotropic. To model an isotropic damage process it suffices to consider a scalar damage variable $\mathrm{d}$. The damage models are under a type of stress-based elastic-damage model, in which the damage is determined by a norm of elastic complementary energy [10]

\section{Oliver's Damage Model}

The damage criterion for the Oliver model introduces a factor which is involved if different stress levels cause initial damage in tension and compression The initial damage threshold, $r_{0}$, can be considered to carry out a similar function to the initial yield stress in an analysis involving an elastic-plastic material. However, in a damage analysis, the value 
of the damage threshold influences the degradation of the elastic modulus matrix. A value for the initial damage threshold $\left(r_{0}\right)$ may be obtained from:

$$
r_{o}=\frac{\sigma_{t}}{\mathrm{E}^{0.5}}
$$

Where $\sigma_{t}$ is the uniaxial tensile stress at which damage commences and $E$ is the undamaged Young's modulus. The damage accumulation functions for each model are given by:

$$
G(r)=1-\frac{r_{o}}{r_{t}} \operatorname{Exp}\left[\lambda\left(1-\frac{r_{o}}{r_{t}}\right)\right]
$$

Where $r_{o}$ and $r_{t}$ are initial and progress damage threshold, for no damage, $G(r)=0$, the characteristic material parameter, $\lambda$ would generally be obtained from experimental data. However, a means of computing material parameter $(\lambda)$ has been postulated for the Oliver model:

$$
\lambda=\left[\frac{G_{f} E}{L_{c h} \sigma_{t}^{2}}-\frac{1}{2}\right]^{-1}
$$

Where $G_{f}$ is the fracture energy per unit area, $L_{c h}$ is a characteristic length of the finite element which can be approximated by the square root of the element area, ( $L_{c h}$ from 0.05 to 0.15$)$. The Damage ratio is the ratio of the tensile stress to compressive stress that causes initial damage in tension and compression [10].

$$
D_{r}=\frac{\sigma_{c}}{\sigma_{t}}
$$

\section{RESULTS AND DISCUSSION}

The load-deformation curves with failure mechanisms give out an indication to determine how and when forces and moments change throughout the structures. This can then be used to determine the energy, which is an important input for the design of vehicle structures. Load-displacement curves were obtained using LUSAS finite element code. A comparison of load-displacement curves have been made to initial crushing load, highest crushing load, mean crushing load and load carrying capacity for all the models of semicone angles of $4,8,12,16$, and 20 degrees. The load-displacement relations of these structures are collected and shown in Figure 3. From these relations, the results included the initial failure load for each specimen, the mean crushing load, highest crushing load (maximum crushing load) and crush energy absorption that represented the area under the curve.

\section{Effect of cone vertex angle}

For the crushing analysis, the main difference seen in the shapes of the crush load vs. crush displacement curves is that the tubes with semi-cone angle of 4 degrees generally 
had higher initial peaks than the other cones. Figure 3 shows the load-displacement response of conical shells for solid steel cone slip axially. From the figures, it can be noticed that the conical shell with semi cone angle of 8 degrees has the highest resistance. The crushing force at pre-initial crush stage increases almost linearly until its first peak value of $8.2 \mathrm{kN}$ at $0.13 \mathrm{~mm}$ displacement. Matrix failure mechanism of micro cracking is initiated at the top end of the cone; this led the load-displacement curve to small drop from $8.2 \mathrm{kN}$ to $7.1 \mathrm{kN}$ at $0.35 \mathrm{~mm}$ displacement $(\mathrm{mm})$. This occurs because of matrix cracking and tearing failure mode in most inner cone wall layer at small end of cone. Then the load rises and reaches to $9.2 \mathrm{kN}$ at $2.17 \mathrm{~mm}$. Then, load-displacement curve behaviour becomes almost stable and it's fluctuating about $9.5 \mathrm{kN}$ from $2.17 \mathrm{~mm}$ displacement to the end of crushing during the post crush stage. The mean crush load $\left(P_{m}\right)$ value was $9.2 \mathrm{kN}$. However, in pre-initial crush stage no damage is visible through the finite element analysis and the elastic energy absorbed by conical shell. While in post crush stage, the energy absorbing mechanisms were found to be significantly depending on the specimen failure modes scenario.

\section{Initial Failure Load $\left(\mathbf{P}_{\mathrm{i}}\right)$}

The initial failure load is defined as the first point where the load abruptly decreases after the elastic linear increase of load. As the crushing begins, the load quickly rises to a peak value, and then drops off slightly. The initial failure load for each test has been obtained directly from the load-displacement curve as shown in Fig. 3. From the curve obtained Fig. 4 , it appears that the initial failure load was decreasing with the increase of semi-vertex angle of cone. These results are also listed in Table 2.

\section{Mean Crushing Load $\left(\mathbf{P}_{\mathrm{m}}\right)$}

The mean crushing load is the average crush load which can be obtained by averaging the crush loads values over the crush displacements through the post-crush region. It appears from Fig. 5 that the mean crushing load also decreases as the semi-cone angle of cone increases.

\section{Energy Absorption Capability}

The energy absorption represents the area under the load-displacement curve. From Equations 3, 5 and 7, two types of energy absorption, during slipping solid cone into conical shells were measured. These are the energy absorbed per unit mass (SEA) and energy absorbed per unit volume $\left(E_{v}\right)$. Figure 6 represents the relation between specific energy absorption and volumetric energy absorption as a function of semi-cone angles of composite conical shell. It's interested to note that the model with semi-cone angle $\beta$ of 8 degrees exhibited more resistance to slipping the solid steel cone through the crush, that means more stable deformation as well as structural integrity. This resulting in higher energy absorption compared with other models. One of more important observation is that most of energy absorption process occurred in post-crush stage as clearly shown from Figure 3 that the post-crush stage for semi-cone angle $\beta$ of 8 degrees was more stable than that for $\beta$ of $4,12,16$ and 20 degrees and during this stage, The specific energy 
absorbed by the cone with semi-cone angle $\beta$ of 8 degrees was $1.29 \mathrm{~kJ} / \mathrm{kg}$. These results for crush energy absorption were also tabulated for all the tests in Table 2. From Table 2 the specific energy absorption of $\beta 8^{\circ}$ was quite high compared with the other cones. As mention earlier the volumetric energy absorption capability $\left(E_{v}\right)$ was calculated used Equation 7 The presence of the resistance mechanism in $\beta 8^{\circ}$ increases their crashworthiness parameters. From the energy absorption capabilities and crashworthiness parameters points of view, one can deduce that the composite conical shells with semicone angle $\beta$ of 8 degrees have superior energy absorption compared to the other cones.

\section{Failure Modes}

The crushing mode was the most common crush mode seen in the shell with semi cone angle $(\beta)$ of $4,8,12,16$ and 20 degrees (Figs. 7, 8, 9, 10 and 11), the accumulation of local damage at the contact between the solid cone and the conical shell wall is evident. With continued slipping of the solid cone and growth of damage, the innermost layer experiences compression state. This resulted in that the outer most layers materials properties degraded quickly, and the innermost layer begins to tear away. The tearing failure mode was occurred in longitudinal fibres and occurs near the contact area between the solid steel cone and the conical shell wall. Subsequently, the tearing failure becomes the predominant mode of damage, and proceeds down along the shell generator as the solid steel cone travel increases.

\section{CONCLUSION}

The reasons for selecting these types of cone to be used for crashworthiness were absorb a large amount of energy during crushing and establish a crush zone that will propagate through the Material. This is usually attained by introducing a high stresses generated at one end of the tube or based trigger mechanisms (such as cone, chamfer).In both cars and aerospace applications, the high specific properties of composite materials make them very attractive candidates for these features

The objective of this research was to compare crashworthiness parameters and how the energy absorption characteristics were changed by varying semi-cone angle of circular cone. The system was designed by slipping a solid cone into composite cone. The three important energy absorption measures were investigated: the specific energy absorption (SEA), the ratio of the peak load to the average load and volumetric energy absorption. The geometry had a significant effect on the energy absorption. Tearing damage mode has been identified; this behaviour is beneficial in that the structure is capable of absorbing impact energy in the form of material separation. Conical shells crushed shown capable of absorbing considerable energy in uniform load-displacement behaviour. The energy absorption capability of semi cone angle $\beta=8^{\circ}$ subjected to slipping test was greater than the energy absorption of semi cone angles 12, 16 and 20.

Comparing these results with the others researcher [Ref. No. 3], It can be concluded that The conical shell lead to a high energy absorption level 


\section{ACKNOWLEDGEMENTS}

The authors wish to thank University of Malaya for the financial support for this research programme.

\section{REFERENCES}

[1] A. Czekanski, M.S. Attia. et al. On the use of a new cell to model geometric asymmetry of metallic foams, International journal of Finite Elements in Analysis and Design 2005; 41: $1327-1340$

[2] [2] Shujuan Houa et al. Design optimization of regular hexagonal thin-walled columns with crashworthiness criteria, int. journal of Finite Elements in Analysis and Design 2007; 43:555 - 565

[3] E. Mahdia and H. Sultan et al. Experimental optimization of composite collapsible tubular energy absorber device int. journal of Thin-Walled Structures 2006; 44:1201-1211

[4] [4] Farley G. L. and R. M. Jones. Crushing Characteristics of Continuous FibreReinforced Composite Tubes, Journal of Composite Materials 1992; 26:37-50

[5] Fleming, D. C. and A. J. Vizzini. The Effect of Side Loads on the Energy Absorption of Composite Structures, Journal of Composite Materials, 1992; 26:486-499

[6] [6] Fleming, D. C. and A. J. Vizzini. Tapered Geometries for Improved Crashworthiness under Side Loads, Journal of the American Helicopter Society 1993; 38:38-44

[7] E.mahdi, A.M.Hamouda and B. B Sahari. Axial and lateral crushing of the filament wound laminated composite curved compound system: Journal of Adv. Comp. Mater. 2002; 11: 171-192

[8] Fleming, D. C. The Energy Absorption of Graphite/Epoxy Truncated Cones, Master's Thesis, University of Maryland 1991

[9] Sen, J. K. and C. C. Dremann. Design Development Tests for Composite Crashworthy Helicopter Fuselage, 1985; SAMPE Q

[10] LUSAS/standard User's Manual, LUSAS theory manual, version 13.5.

Table1. Material Properties of glass fibre/Epoxy

\begin{tabular}{|c|c|c|}
\hline Material Property & Symbol & Property Value \\
\hline Young's Modulus in x-direction & $\mathrm{E}_{\mathrm{x}}$ & $20 \mathrm{GPa}$ \\
\hline Young's Modulus in y-direction & $\mathrm{E}_{\mathrm{y}}$ & $19 \mathrm{GPa}$ \\
\hline Young's Modulus in z-direction & $\mathrm{E}_{\mathrm{z}}$ & $8 \mathrm{GPa}$ \\
\hline Shear modulus in xy-direction & $\mathrm{G}_{\mathrm{xy}}$ & $4.2 \mathrm{GPa}$ \\
\hline Shear modulus in yz-direction & $\mathrm{G}_{\mathrm{yz}}$ & $4.2 \mathrm{Gpa}$ \\
\hline Shear modulus in xz-direction & $\mathrm{G}_{\mathrm{xz}}$ & $4.2 \mathrm{Gpa}$ \\
\hline Poisson's Ratio & $\mathrm{V}_{12}$ & 0.13 \\
\hline Mass density & $\mathrm{M}$ & $1900 \mathrm{~kg} / \mathrm{m}^{3}$ \\
\hline
\end{tabular}




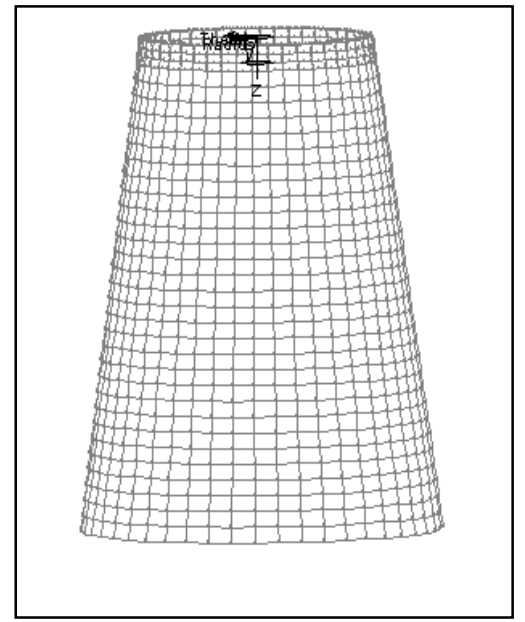

Fig.1: Typical Mesh Generation of WRL Conical Shell

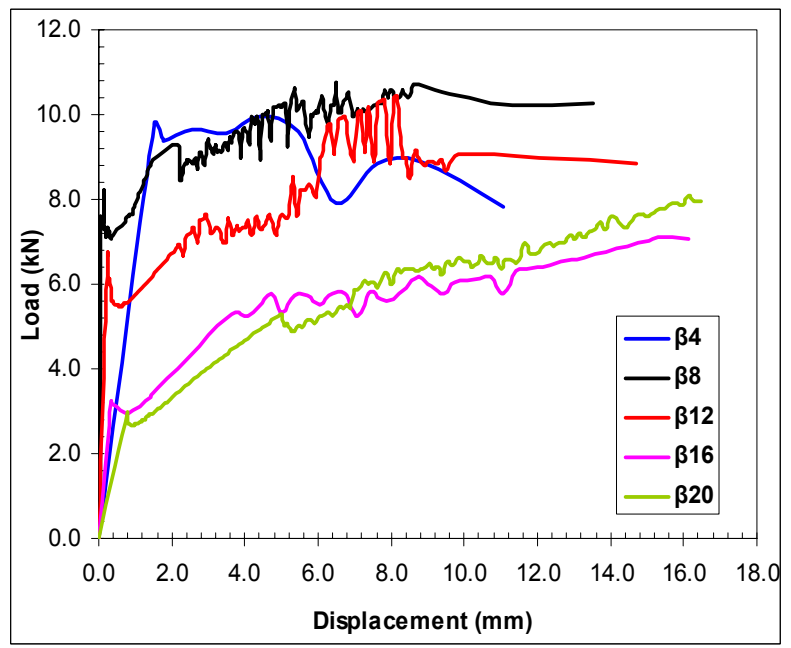

Fig.3: Load-displacement curves of WRL for different Semi-cone angles

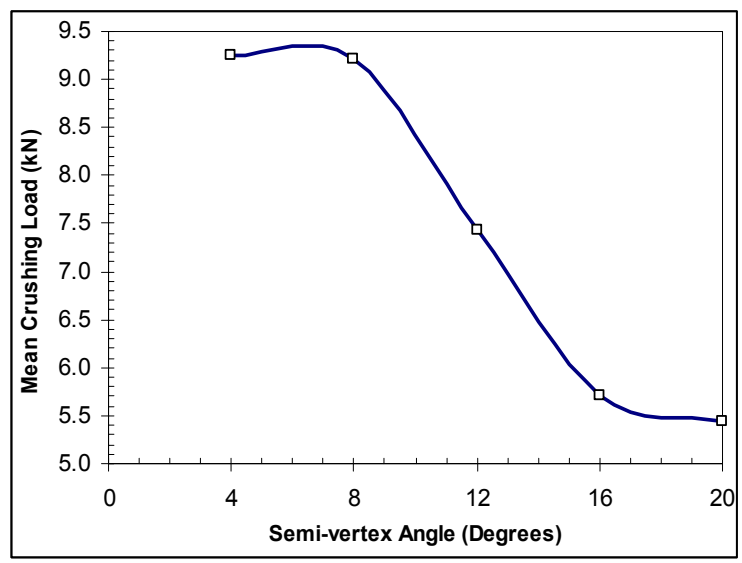

Fig. 5: Mean Load Vs semi-cone angle.

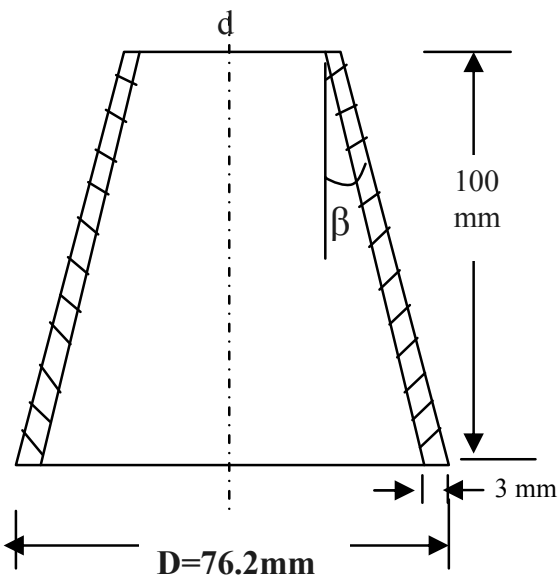

a) Typical Sketch of Conical Shell

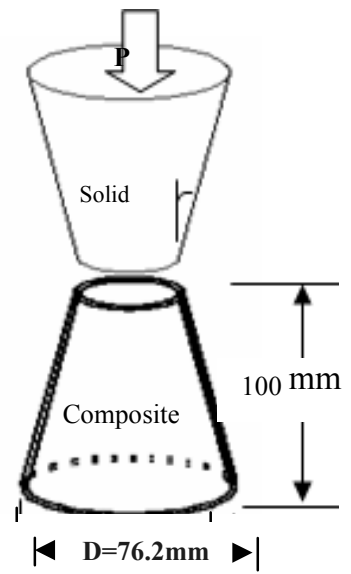

b) Slipping of solid into

Fig. 2: Typical Sketch of Conical Shell Model and Composite Conical Shell under Slipping Test

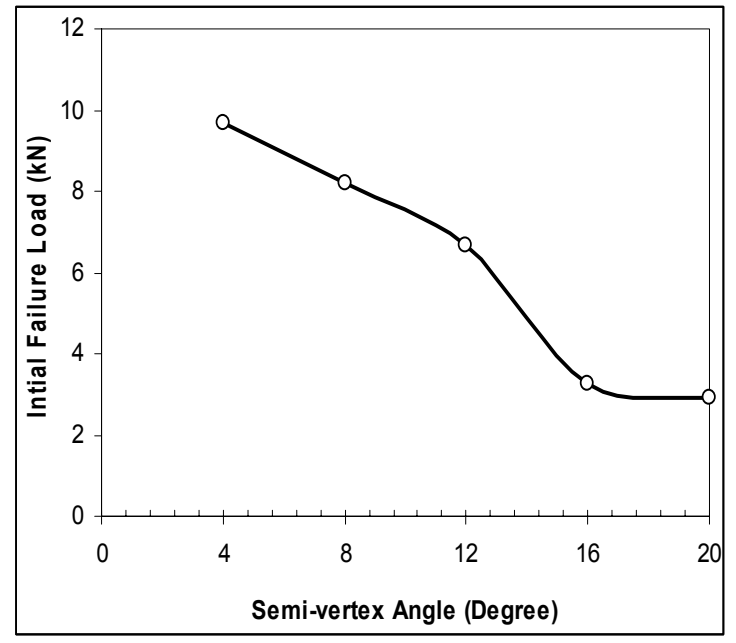

Fig. 4: Initial Failure Load Vs semi-vertex Angles

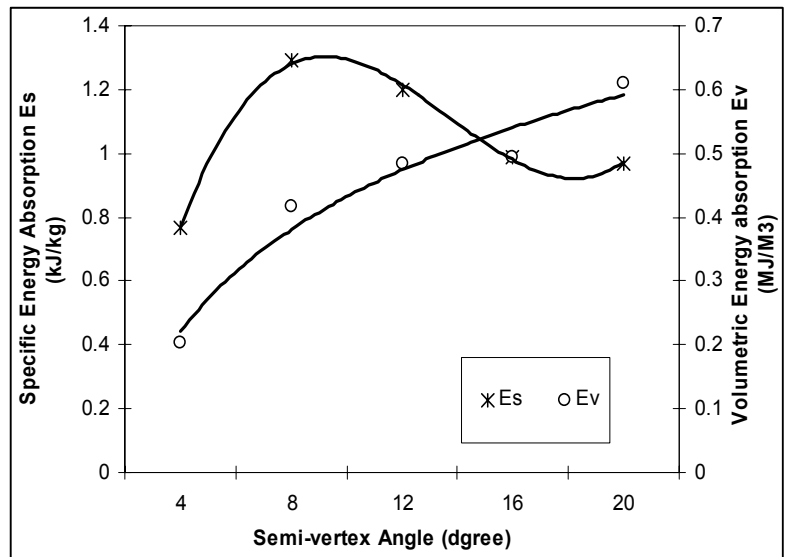

Fig. 6: Energy Absorption Capabilities VS Semi-cone angle. 
Table 2: measured crashworthiness parameters for the slipping of solid steel cone into the woven roving wound laminated glass/epoxy conical shells

\begin{tabular}{|c|c|c|c|c|c|c|c|c|}
\hline \multirow{2}{*}{$\begin{array}{c}\text { Cone } \\
(\text { ID })\end{array}$} & $P_{\mathrm{i}}$ & $\mathrm{P}_{\mathrm{m}}$ & $\mathrm{P}_{\mathrm{pH}}$ & $\mathrm{IFI}$ & $\mathrm{CFE}$ & $\mathrm{SE}$ & $\mathrm{E}_{\mathrm{s}}$ & $\mathrm{E}_{\mathrm{v}}$ \\
\cline { 2 - 10 } & \multicolumn{3}{|c|}{$(\mathrm{kN})$} & \multicolumn{2}{c|}{$\mathrm{kN} / \mathrm{kN}$} & $\mathrm{mm} / \mathrm{mm}$ & $\mathrm{kJ} / \mathrm{kg}$ & $\left(\mathrm{kJ} / \mathrm{m}^{3}\right)$ \\
\hline$\beta 4^{\circ}$ & 9.70 & 9.26 & 9.9 & 0.85 & 0.91 & 0.74 & 0.76 & 202.75 \\
\hline$\beta 8^{\circ}$ & 8.21 & 9.22 & 9.9 & 0.83 & 0.94 & 0.76 & 1.29 & 417.1 \\
\hline$\beta 12^{\circ}$ & 6.69 & 7.43 & 10.2 & 0.66 & 0.72 & 0.65 & 1.20 & 484.75 \\
\hline$\beta 16^{\circ}$ & 3.25 & 5.71 & 7.0 & 0.45 & 0.80 & 0.66 & 0.99 & 493.6 \\
\hline$\beta 20^{\circ}$ & 2.92 & 5.44 & 8.2 & 0.35 & 0.67 & 0.52 & 0.97 & 608.9 \\
\hline
\end{tabular}

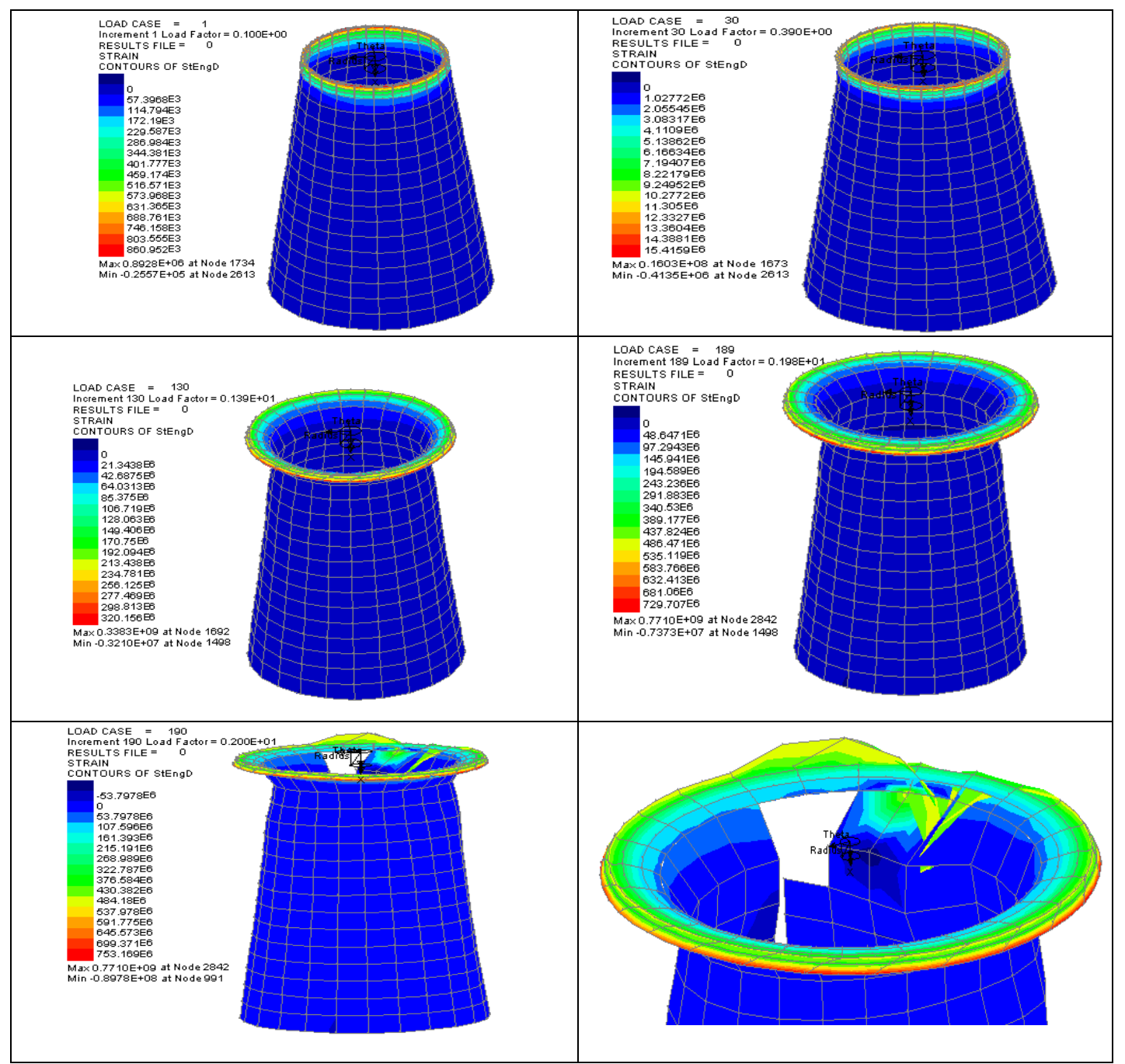

Fig. 7: deformed shape of semi cone angle with $\beta=8^{\circ}$ subjected to the slipping system 